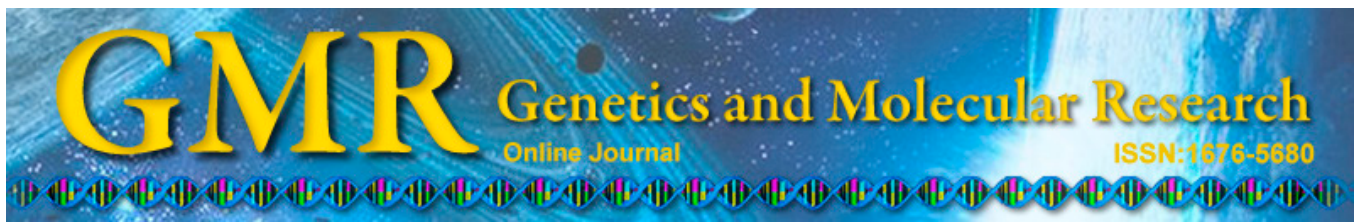

\title{
Allelopathy of the invasive plant Bidens frondosa on the seed germination of Geum japonicum var. chinense
}

\author{
X.F. Wang ${ }^{1}$, D. Hassani ${ }^{3}$, Z.W. Cheng ${ }^{1}$, C.Y. Wang ${ }^{2}$ and J. Wu ${ }^{2}$ \\ ${ }^{1}$ School of Life and Environment Science, Huangshan University, Huangshan, \\ China \\ ${ }^{2}$ Landscape Bureau of Huangshan Scenic Spots, Anhui, China \\ ${ }^{3}$ The Key Laboratory of Forest Genetics and Biotechnology, Nanjing Forestry \\ University, Nanjing, China \\ Corresponding author: X.F. Wang \\ E-mail:wxf74hs@163.com
}

Genet. Mol. Res. 13 (4): 10592-10598 (2014)

Received June 4, 2014

Accepted September 4, 2014

Published December 12, 2014

DOI http://dx.doi.org/10.4238/2014.December.12.22

\begin{abstract}
Five gradient concentrations $(0.02,0.04,0.06,0.08$, and $0.10 \mathrm{~g} / \mathrm{mL}$ ) of leaching liquors from the roots, stems, and leaves of the invasive plant Bidens frondosa were used as conditioning fluid to examine its influence on seed germination conditions of the native plant Geum japonicum var. chinense in Huangshan. All leaching liquors of organs suppressed the seed germination of Geum japonicum var. chinense and reduced the final germination percentage and rate, and increased the germination inhibition rate, with a bimodal dependence on concentration. The leaching liquor inhibited the seed germination significantly at the concentration of $0.02 \mathrm{~g} / \mathrm{mL}$ respectively. The seed germination was also inhibited as the concentration reached to $0.04 \mathrm{~g} / \mathrm{mL}$ and beyond. Hence the allelopathic effects of the organs were significantly enhanced respectively. This phenomenon represented the presence of allelopathy substances in the root, stem and leaf of Bidens frondosa.
\end{abstract}

Key words: Bidens frondosa, allelopathy; Invasive plants; Geum japonicum var. chinense; Seed germination 


\section{INTRODUCTION}

Allelopathy was first proposed by the Austrian scientist Molisch in 1937 (Jiang et al., 2006) and refers to the phenomenon that plants release chemicals into the surroundings, affecting the growth and development of themselves and of other plants (Yu et al., 1991). This is an ecological mechanism for natural chemical regulation and the adaptation of plants in an ecosystem (Lv and Duan, 2005), which affects chemical ecology defense and competition. Allelopathy is an important means of adaptation, survival, and competition, and exists widely in nature; it has become a domestic and international concern, and various studies have been conducted to address these concerns (Jiang et al., 2010). Currently, a number of alien invasive weeds has been confirmed to show allelopathy, such as Solidago Canadensis, and Mikania, among others (Zeng and Luo, 1993; Wang and Zhu, 1996; Hu and Kong, 1997; Shao et al., 2003; Su and Zhu, 2003; Mei et al., 2005; Wan et al., 2011; Lu et al., 2011).

Bidens frondosa is the Asteraceae Bidens annual herb that grows to $30-150 \mathrm{~cm}$ and shows a high reproductive ability. A normal developing plant can produce hundreds of thousands of seeds, which are large, light, and have barbs. They fall from the plant easily upon reaching maturity and can be dispersed through wind and currents, as well as by adhering to animals and humans.

The bryophyte $B$. frondosa is also highly adaptable and is widely distributed in nature. It is capable of growing in wet or shallow water conditions in temperate or subtropical climates, as commonly observed in Huangshan, China. It also may invade Huangshan scenic locations. Geum japonicum var. chinense is native to Huangshan and is a perennial herb that grows in or near hillside meadows, fields, rivers, thickets, and thin forest (Flora Editorial Board of Chinese Academy of Sciences, 2004).

Based on a 4-year investigation from 2009-2013 of Huangshan Scenic locations, a considerable amount of $B$. frondosa was found to have invaded the natural distribution area of G. japonicum var. chinense, indicating sympatric distribution. In this study, G. japonicum var. chinense seeds were used as the receptor and the leaching liquor of the roots, stems, and leaves of $B$. frondosa were used as the conditioning fluid. We examined the allelopathy of $B$. frondosa and developed technical support for using the allelochemicals for the production of biological herbicides with new target points or for the synthetic template of new chemical herbicides. It is important to reduce the dependence of agricultural ecosystems on chemical pesticides and provide a reference for preventing the alien weed from invading scenic locations in Huangshan.

\section{MATERIAL AND METHODS}

\section{Plant materials}

The seeds of $B$. frondosa and G. japonicum var. chinense were respectively sampled from the city of Huangshan and the Beihai Scenic Area in September and October of 2011.

\section{Optimum temperature and light conditions for seed germination}

Through a single factor experiment of seed germination of G. japonicum var. chinense, the optimum temperature and light conditions were determined for seed germination, 
which were similar to the environmental conditions in the allelopathic experiment.

\section{Water temperature setting}

Seeds of G. japonicum var. chinense were screened and disinfected using hydrogen peroxide. The seeds were then sterilized in 5 culture dishes and covered with a layer of filter paper and absorbent cotton. Fifty seeds were chosen randomly, placed in each dish, and placed in an illumination incubator at temperatures of $20,22,24,26$, and $28^{\circ} \mathrm{C}$ while keeping other environmental conditions consistent. The germination was checked once a day and recorded. This experiment was repeated 3 times.

\section{Light setting}

Based on the above experiment, a culture under dark conditions was used as a control. The 5 temperatures were considered to be the experimental groups.

\section{Preparation of leaching liquor from $B$. frondosa}

B. frondosa were rinsed using the distilled water. The roots, stems, and leaves were cut into 3-5 mm pieces. Next, $20 \mathrm{~g}$ each sample was mixed with $200 \mathrm{~mL}$ sterile distilled water to prepare the liquor. Samples were shaken for 10 min every $12 \mathrm{~h}$. After 48 h, 4 layers of sterile gauze were used to filter the aqueous extracts and remove plant residues. Samples were centrifuged for $15 \mathrm{~min}$ at $3000 \mathrm{rpm}$ to obtain the mother liquor of leaching liquor with $0.10 \mathrm{~g} / \mathrm{mL}$ concentration (Wang et al., 2012). The mother liquor was diluted to $100,80,60,40$, and $20 \%$ with sterile distilled water and the 3 organ samples were treated with the 5 concentration of mother liquors. The control group was treated with sterile distilled water and placed in freezer in $\left(1^{\circ} \mathrm{C}\right)$.

\section{Determination of germination of Geum japonicum var. chinense seeds}

The Petri dish and filter paper were sterilized. The seeds were also disinfected for 10 min with $10 \% \mathrm{H}_{2} \mathrm{O}_{2}$ and then washed 3 times with distilled water ( 3 min each wash). Fifty $G$. japonicum var. chinense seeds were selected and placed in the filter paper of the Petri dish. Next, $5 \mathrm{~mL}$ leach liquor at the 5 different concentrations was added to each of the 3 organ samples, while $5 \mathrm{~mL}$ sterile distilled water was added to the control sample. This procedure was repeated 3 times. The Petri dishes were wrapped to prevent water evaporation and contamination, and then randomly placed into illumination incubator at $26^{\circ} \mathrm{C}$ (determined through the single-factor test). Seed germination was monitored every $24 \mathrm{~h}$ and terminated when there were no newly germinated seeds for 5 days. Germination was considered to occur when the radicle broke the seed coat by $1-2 \mathrm{~mm}$.

\section{Data analysis}

The treatment group and control group were analyzed based on a previously described equation (Du et al., 2009). 


$$
\begin{array}{cc}
\mathrm{GR}=\mathrm{G} / 50 & (\text { Equation 1) } \\
\mathrm{RG}=\Sigma \mathrm{i} 1\left(\mathrm{~N}_{\mathrm{i}} / \mathrm{D}_{\mathrm{i}}\right) & (\text { Equation 2) } \\
\mathrm{PI}(-)=\mathrm{UG}(\mathrm{AE}) / \mathrm{UG}(\mathrm{CK})-1<0 & (\text { Equation 3) } \\
\mathrm{PS}(+)=\mathrm{UG}(\mathrm{AE}) / \mathrm{UG}(\mathrm{CK})-1>0 & (\text { Equation 4) }
\end{array}
$$

In these formulas, $G R$ represents germination rate, $G$ represents the number of germinated seeds, $U G$ represents the ultimate germination rate, $R G$ represents seed germination rate, $D_{i}$ represents the number of days, $N_{i}$ represents the number of germinated seeds on the $\mathrm{i}^{\text {th }}$ day, $P I$ represents the inhibition ratio of seed germination, $P S$ represents the promotion rate of seed germination, $U G(\mathrm{AE})$ represents the ultimate germination rate after treatment with leaching liquor, $U G(\mathrm{CK})$ represents the ultimate germination rate in th econtrol group, $P I$, and $P S$ is the conversion into percentages.

\section{RESULTS}

\section{Influence of different leaching liquors on germination of $G$. japonicum var. chi- nense seeds}

Based on the test results, the influence of the leaching liquor with different concentrations of 3 organs from $B$. frondosa on the germination of $G$. japonicum var. chinense seeds is shown in Table 1.

Table 1. Influence of leaching liquor containing different concentrations of roots, stems, and leaves of Bidens frondosa on the germination of Geum japonicum var. chinense seeds.

\begin{tabular}{lcccrrr}
\hline Treatment & \multicolumn{5}{c}{ Germination } \\
\cline { 2 - 6 } & Distilled water & $0.02 \mathrm{~g} / \mathrm{mL}$ & $0.04 \mathrm{~g} / \mathrm{mL}$ & $0.06 \mathrm{~g} / \mathrm{mL}$ & $0.08 \mathrm{~g} / \mathrm{mL}$ & $0.10 \mathrm{~g} / \mathrm{mL}$ \\
\hline Root & 98.00 & $98.00 \pm 1.63$ & $46.00 \pm 2.83$ & $58.00 \pm 1.63$ & $46.00 \pm 2.83$ & $24.00 \pm 4.90$ \\
Stem & 98.00 & $76.00 \pm 0.82$ & $56.00 \pm 2.45$ & $74.00 \pm 2.83$ & $50.00 \pm 1.63$ & $24.00 \pm 3.27$ \\
Leaf & 98.00 & $95.00 \pm 2.45$ & $54.00 \pm 4.89$ & $68.00 \pm 1.63$ & $44.00 \pm 2.83$ & $26.00 \pm 3.27$ \\
\hline
\end{tabular}

Table 1 indicates that leaching liquor containing different concentrations of various organs significantly inhibited seed germination. Generally, germination rate decreased with increasing leaching liquor concentration. When the concentration was $0.10 \mathrm{~g} / \mathrm{mL}$, germination rate reached its lowest rate; the difference in the leaching liquors from roots, stems, and leaved at different concentrations was highly significant $(\mathrm{P}<0.05)$; when the concentration was $0.02 \mathrm{~g} / \mathrm{mL}$, the stem leaching liquor inhibited germination more significantly than using liquors of roots and leaves; however, when the concentration was $0.04 \mathrm{~g} /$ $\mathrm{mL}$, seed germination was inhibited more strongly than when the concentration was 0.06 $\mathrm{g} / \mathrm{mL}$. This requires further study. 


\section{Influence of different concentrations of leaching liquor on the germination rate of G. japonicum var. chinense seeds}

The germination rate of allelopathy was calculated according to the test results, as shown in Table 2.

Table 2 shows that the germination rate of the control group (distilled water) was 48.64 seeds/day. When the concentration of root leaching liquor was $0.02 \mathrm{~g} / \mathrm{mL}$, the difference in seed germination rate between the experimental and control groups was not very significant $(\mathrm{P}>0.05)$. The leaching liquors of other organs of different concentrations showed significant or extremely significant differences in germination rate. With increasing leaching liquor concentration, germination was more strongly inhibited; the maximum effect was observed at a leaching liquor concentration of $0.10 \mathrm{~g} / \mathrm{mL}$.

Table 2. Influence of leaching liquor containing different concentrations of roots, stems, and leaves of Bidens frondosa on the germination rate of Geum japonicum var. chinense seeds.

\begin{tabular}{lcccccc}
\hline Treatment & \multicolumn{5}{c}{ Rate of germination (seeds/day) } \\
\cline { 2 - 6 } & Distilled water & $0.02 \mathrm{~g} / \mathrm{mL}$ & $0.04 \mathrm{~g} / \mathrm{mL}$ & $0.06 \mathrm{~g} / \mathrm{mL}$ & $0.08 \mathrm{~g} / \mathrm{mL}$ & $0.10 \mathrm{~g} / \mathrm{mL}$ \\
\hline Root & $48.64 \pm 0.54$ & $47.75 \pm 0.21$ & $13.92 \pm 0.07$ & $18.83 \pm 0.10$ & $17.10 \pm 0.33$ & $7.44 \pm 0.05$ \\
Stem & $48.64 \pm 0.54$ & $16.36 \pm 0.52$ & $14.67 \pm 0.17$ & $21.82 \pm 0.68$ & $11.72 \pm 0.27$ & $5.32 \pm 0.24$ \\
Leaf & $48.64 \pm 0.53$ & $35.74 \pm 0.42$ & $17.70 \pm 0.25$ & $21.04 \pm 0.44$ & $13.26 \pm 0.20$ & $6.58 \pm 0.07$ \\
\hline
\end{tabular}

\section{Inhibition/promotion of leaching liquor on G. japonicum var. chinense seeds}

The ratio of germination to the promotion ratio of seeds was determined (Table 3).

As shown in Table 3, in addition to the root extract concentration of $0.02 \mathrm{~g} / \mathrm{mL}$, leaching liquor of other concentrations inhibited seed germination; with increasing concentration, the absolute value of germination rate also increased. When the leaching liquor of roots, stems, and leaves was the highest concentration tested of $0.10 \mathrm{~g} / \mathrm{mL}$, seed germination inhibition rates were $-75.51,-75.51$, and $-73.47 \%$, respectively. Generally, leaching liquor inhibited seed germination, but the inhibition was bimodal; when the concentration was $0.04 \mathrm{~g} / \mathrm{mL}$ and 0.10 $\mathrm{g} / \mathrm{mL}$, the inhibition rate of seed germination had a larger absolute value.

Table 3. Influence of roots, stems, and leaves of Bidens frondosa on the germination rate/promotion rate of
Geum japonicum var. chinense seeds.
\begin{tabular}{lcccccc}
\hline Treatment & \multicolumn{7}{c}{ Percentage inhibition (-) or promotion (+) } \\
\cline { 2 - 7 } & Distilled water & $0.02 \mathrm{~g} / \mathrm{mL}$ & $0.04 \mathrm{~g} / \mathrm{mL}$ & $0.06 \mathrm{~g} / \mathrm{mL}$ & $0.08 \mathrm{~g} / \mathrm{mL}$ & $0.10 \mathrm{~g} / \mathrm{mL}$ \\
\hline Root & 0 & 0 & -53.06 & -40.82 & -53.06 & -75.51 \\
Stem & 0 & -22.45 & -42.86 & -24.49 & -48.98 & -75.51 \\
Leaf & 0 & -3.06 & -44.90 & -30.61 & -55.10 & -73.47 \\
\hline
\end{tabular}

\section{DISCUSSION}

Our results showed that the $B$. frondosa significantly inhibited the germination of $G$. japonicum var. chinense when the concentration of the stem leaching liquor was greater than $0.02 \mathrm{~g} / \mathrm{mL}$ and those of the root and leaf leaching liquors were greater than $0.04 \mathrm{~g} / \mathrm{mL}$. The inhibition reached a maximum at a concentration of $0.10 \mathrm{~g} / \mathrm{mL}$. All organs of $B$. frondosa 
inhibited the germination of G. japonicum var. chinense seeds at different concentrations of leaching liquor, reducing the seed germination rate. These results support the allelopathic effects on plant growth, which is consistent with the phenomenon observed in the natural environment. Additionally, the strength of allelopathy differed among plant organs and with varying concentrations of leaching liquor; generally, the effect was stronger with increased leaching liquor concentration. $B$. frondosa can release water-soluble substances to create an environment conducive to their growth by rain and other effects to enhance their survival, explaining the invasion mechanism of $B$. frondosa (Du et al., 2009).

In terms of inhibition of seed germination of G. japonicum var. chinense, the leaching liquors from the organs of $B$. frondosa not only reduced the final germination rate and increased the inhibition rate of seed germination, but also reduced the seed germination rate. The allelopathy of plants is widespread in nature and plays an important role in the formation of dominant species, community succession, and revegetation. Plants interact with each other by releasing secondary metabolism compounds to protect their favorable ecological environment (Gu et al., 1998). Terpenoids are abundant in higher plants, mainly in the form of volatile oil, which can protect against damage from insects. These substances can produce allelopathic effects in other plants after their release into the environment (Hu and Kong, 2002). The toxicity of plant terpenoid compounds is selective, which is manifested as the inhibition of plant germination and growth at high concentrations. Furthermore, the inhibition is gradually strengthened with increasing concentrations of allelochemicals. This can promote growth at low concentrations, which has been observed in allelopathy research of odorata, cairica, and Wedelia (Zeng et al., 1996; Liu et al., 1997; He et al., 2002; Fang et al., 2005). Further in-depth analysis of the chemical composition and release mechanism of allelopathy of $B$. frondosa is needed.

The leaching liquors of $B$. frondosa organs contain water-soluble allelopathic substances. With respect to the various organs of $B$. frondosa, the leaching liquors of the root, stem, and leaf inhibited seed germination to varying degrees at the same concentration, indicating there are some differences between the allelopathy of different plant parts, which may be due to differences in their allelochemical levels. The allelopathy strength of the leaching liquors of various organs is generally stronger with increasing leaching liquor concentrations, which is relatively strong at a concentration of $0.04 \mathrm{~g} / \mathrm{mL}$.

\section{ACKNOWLEDGMENTS}

Research supported by the Science Research Project of Education Department in Anhui (\#KJ2011Z365) and Production and Research Project of Huangshan University and Garden Bureau of Huangshan Scenic Landscaping.

\section{REFERENCES}

Du W, He CQ, Chen YL and Liang X (2009). Allelopathic effect of spartina aqueous extracts of invasive plant on the lettuce. J. Environ. Sci. 29: 869-875.

Fang F, Mao W and Guo SL (2005). Research on the allelopathy of invasive weed Erigeron annuus. J. Plant Res. 25: 449-452.

Flora Editorial Board of Chinese Academy of Sciences (2004). Flora of China. Science Press; Beijing, 114-326.

Gu WX, Duan SS and Luo SM (1998). Ecological characteristics of terpenoids and its allelopathy on plants. J. South China Agric. Univ. 19: 108-112. 
He YB, Zhang MX, He TY and Gu WX (2002). Preliminary study of allelopathy odorata. J. South China Agr. Univ. 23: 60-63.

$\mathrm{Hu} \mathrm{F}$ and Kong CH (1997). Research on the allelopathy of Ageratum: I. allelopathy of aqueous extracts and identification of allelochemicals isolation. J. Appl. Ecol. 8: 304-308.

$\mathrm{Hu} \mathrm{F}$ and Kong CH (2002). Research on the Ageratum allelopathy VI. influence of meteorological conditions on Ageratum allelopathic effects. J. Appl. Ecol. 13: 76-80.

Jiang GB and Zeng RS (2006). Review of allelochemicals and the collection methods. Henan Agr. Sci. 38: 23-27.

Jiang GB, Chen SX, Huang DY and Wang WZ (2010). Allelopathy of extracts of several plants on growth of weeds. $J$. Jiangsu Agr. Sci. 26: 292-295.

Liu W, Hou RZ, Ye H and Shi YR (1997). Allelopathy of Ipomoea cairica. J. South China Agr. Univ. 18: 119-122.

Lu ZG, Zhou WJ, Zheng BY and Jiang Q (2011). Allelopathy of bidentis on two kinds of vegetable seeds and seedling. Grassland Sci. 28: 251-254.

Lv FT and Duan YM (2005). Application of allelopathy in production. Biol. Bull. 40: 21-23.

Mei LX, Chen X and Tang JJ (2005). Allelopathy of weed Canada goldenrod on invasive plants. J. Appl. Ecol. 16: 23792382.

Shao H, Peng SL, Zhang C and Xiang YC (2003). Mikania allelopathy of Mikania micrantha. J. Ecol. 22: 62-65.

$\mathrm{Su} \mathrm{L}$ and Zhu JS (2003). Influence of leaching liquor of hollow lotus rhizome on the germination rate of several common weed seed. Weed Sci. 21: 8-9.

Wan FH, Liu WX, Guo JY and Qiang S (2011). Research on the invasion mechanism of exotic plant Ageratina adenophora and the control strategy. Chin. Sci. 41: 14-21.

Wang DL and Zhu XR (1996). Research on the allelopathy of ragweed. J. Ecol. 16: 1-19.

Wang XF, Qian QY, Wang ZY and Wu L (2012). Allelopathy of Galinsoga on the Geum japonicum var. chinense of native plants in Huangshan. J. Nanjing Forestry Univ. 36: 145-148.

Yu FL, Ma HH and Kong LS (1991). Research on the allelopathy of Ordosica volatile oil. J. Plant Ecol. 23: 345-350.

Zeng RS and Luo SM (1993). Research on the Allelopathy of Lemongrass, Conyzoides and Bidens. J. South China Agr. Univ. 14: 19-14.

Zeng RS, Lin XL and Luo SM (1996). Biochemical allelopathy of Wedelia chinensis and the isolation identification of its substrates. J. Ecol. 16: 20-27. 